\title{
Original Article \\ CD117 expression in diffuse large B-cell lymphomas: Fact or fiction?
}

\author{
Efsevia Vakiani, Giorgio Cattoretti, Adriana I. Colovai, Vundavalli V. Murty, Bachir Alobeid and \\ Govind Bhagat \\ Department of Pathology, Columbia University, New York, NY, USA
}

CD117 (KIT) is expressed in a variety of hematopoietic neoplasms but there are a paucity of data regarding its expression in diffuse large B-cell lymphomas (DLBCL). The purpose of the present paper was to describe the authors' experience of two CD117+ DLBCL (one of follicle center-cell origin and one nasal Epstein-Barr virus (EBV)- plasmablastic lymphoma associated with lytic bone lesions), as determined by tissue immunohistochemistry and flow cytometry. The CD117 expression in DLBCL was further evaluated using tissue microarrays and seven additional plasmablastic lymphomas, using two commercially available anti-CD117 antibodies (Ab-1, Oncogene and A4502, DakoCytomation). Membranous \pm cytoplasmic staining was seen with Ab-1 in 24/65 (37\%) DLBCL, including 21/56 microarray DLBCL, two index cases, and 1/7 additional plasmablastic lymphomas, with persistent staining in $13 \%$ of microarray DLBCL despite preincubation with KIT peptide. However, A4502 had only membranous staining of the index cases and one additional EBV- plasmablastic lymphoma with medullary disease. The present study suggests that (i) CD117 expression can be detected sporadically in DLBCL of follicle center-cell origin and a subset of plasmablastic lymphomas; (ii) staining for CD117 might help in identifying EBV- plasmablastic lymphomas associated with bone marrow involvement; and (iii) CD117 antibodies should be carefully validated prior to use, because non-specific staining, as observed with $\mathrm{Ab}-1$, could lead to false-positive results.

Key words: CD117, EBV, immunohistochemistry, KIT, Iymphoma, microarray, plasmablastic lymphoma

The c-kit proto-oncogene encodes a 145-160 kDa transmembrane tyrosine kinase receptor (KIT, CD117) that is physiologically expressed in a variety of cells including mast cells, hematopoietic stem cells, melanocytes, germ cells, and the interstitial cells of Cajal. ${ }^{1-3}$ Activation of KIT by its ligand,

Correspondence: Govind Bhagat, MD, Department of Pathology, Columbia University, 630 West 168th Street, VC14-215, NY 10033, New York, USA. Email: gb96@ columbia.edu

Received 17 May 2005. Accepted for publication 22 July 2005. stem cell factor (SCF), plays an important role in the development and function of these different cell lineages. ${ }^{4-8}$ Activating $c$-kit mutations have been implicated in the pathogenesis of tumors derived from these cells including gastrointestinal stromal tumors, ${ }^{9}$ germ cell tumors, ${ }^{10}$ mast cell neoplasms, ${ }^{11}$ and acute myeloid leukemia (AML). ${ }^{12} \mathrm{KIT}$ expression has also been documented in other neoplasms, such as angiomyolipomas, ${ }^{13}$ small cell lung carcinomas, ${ }^{14}$ renal cell carcinomas, ${ }^{15}$ adenoid cystic carcinomas, ${ }^{16}$ nasopharyngeal carcinomas, ${ }^{17}$ breast carcinomas, ${ }^{18}$ and a variety of pediatric solid tumors. ${ }^{19}$ The mechanism and tumorigenic potential of KIT overexpression in these neoplasms is, however, unclear.

Among hematopoietic neoplasms CD117 expression has been documented in AML including granulocytic sarcomas, ${ }^{2,20}$ systemic mastocytosis, ${ }^{21}$ T-cell acute lymphoblastic leukemia, ${ }^{22}$ and multiple myeloma. ${ }^{23}$ Studies have also reported CD117 expression in cases of classical Hodgkin lymphoma ( $\mathrm{cHL})$, in $\mathrm{cHL}$-derived cell lines, and in anaplastic large cell lymphoma (ALCL). ${ }^{24,25}$ More recent reports, however, have refuted these results and demonstrated that KIT expression is exceedingly rare in CD30+ lymphomas. ${ }^{26}$

Diffuse large B-cell lymphoma (DLBCL) is the most common type of adult non-Hodgkin lymphoma (NHL). ${ }^{27} \mathrm{DLBCL}$ is a heterogeneous disease entity with variable clinical presentations, morphology, phenotype, cytogenetic alterations, and gene expression profiles. ${ }^{28-30}$ We encountered two cases of CD117+ DLBCL; one DLBCL of follicle center-cell origin that presented as a soft-tissue mass in the abdominal wall of an HIV+ man and the other a plasmablastic lymphoma that occurred in the nasal cavity of a woman after receiving chemotherapy for a Helicobacter pylori-associated gastric DLBCL. Because contradicting results have been published regarding CD117 expression in lymphomas, ${ }^{24-26}$ and because only a few studies have addressed CD117 expression in DLBCL, ${ }^{20,21,24}$ we decided to investigate the frequency of CD117 expression in DLBCL by staining DLBCL tissue microarrays, as well as seven additional cases of plasma- 
blastic lymphomas, with two different commercially available anti-CD117 antibodies, both of which recognize an epitope on the cytoplasmic domain of CD117.

\section{MATERIALS AND METHODS}

\section{Tissue microarray design}

Two tissue microarray blocks containing a total of 300 cores from 100 samples representing DLBCL, other B-cell NHL, $\mathrm{cHL}$, and control tissues were constructed as described previously. ${ }^{31}$ In addition to DLBCL (74 cases), the microarrays contained cores of tissue representing 14 other B-cell $\mathrm{NHL}$ including, follicular lymphoma $(\mathrm{FL}, n=2)$, chronic lymphocytic leukemia/small lymphocytic lymphoma (CLL/SLL, $n=6$ ), marginal zone B-cell lymphoma (MZBCL, $n=2)$, mantle cell lymphoma (MCL, $n=2)$, and HIV-associated Burkitt lymphoma $(n=2)$, two cases of $\mathrm{cHL}$, and 10 controls. The controls consisted of normal spleen $(n=2)$, tonsil $(n=2)$, brain, thymus, and appendix (one each), and three cell lines (one Epstein-Barr virus (EBV) transformed lymphoblastoid cell line, cb33, and two Burkitt cell lines, BurODHI and BurODHIII). Briefly, diagnostic areas were marked on formalinfixed, paraffin-embedded tissue blocks from each case. A tissue arrayer device (Beecher Instrument, Silver Spring, MD, USA) was used to obtain three $1 \mathrm{~mm}$-diameter cores from cases and controls. Tissue cores from cases and controls were then embedded into nascent paraffin blocks.

\section{Additional plasmablastic lymphomas}

The seven plasmablastic lymphomas consisted of two EBV+ post-transplant plasmablastic lymphomas (one involving small bowel mucosa and one subcutaneous tissue of the forearm), one EBV+ HIV-associated plasmablastic lymphoma of the oral cavity, two EBV+ plasmablastic lymphomas of the nasal cavity, and two EBV- plasmablastic lymphomas (one involving lymph nodes and spleen and one subcutaneous tissue of the chest wall), both of the latter had concurrent bone marrow involvement.

\section{Histology, immunohistochemistry and in situ hybridization}

Hematoxylin-eosin (HE) and immunohistochemical (IHC) staining was performed on $3 \mu \mathrm{m}$ sections of the index cases, tissue microarrays and seven plasmablastic lymphomas. Tonsil and small bowel sections were used as external controls. CD117 staining of all cases was performed after moist heat-induced antigen retrieval under pressure (citrate buffer,
pH 6.5, microwave $7 \mathrm{~min}$ at $100 \%$ and $15 \mathrm{~min}$ at $40 \%$ power level). Endogenous peroxidase was blocked with $10 \%$ hydrogen peroxide followed by incubation with swine serum to inhibit non-specific binding. Two anti-CD117 antibodies were used: A4502 (rabbit polyclonal, DakoCytomation, Carpinteria, CA, USA) that recognizes an epitope on amino acids 963-973 and Ab-1 (rabbit polyclonal, Oncogene, Cambridge, MA, USA) that recognizes an epitope on amino acids 961976. Two dilutions (1:100 and 1:200 for $A b-1 ; 1: 200$ and $1: 400$ for A4502) were tested on controls and the index cases with similar results. Thus, only the higher dilutions (1:200 for Ab-1 and 1:400 for A4502) were used for IHC staining. Staining was performed on an autostainer (Autostainer Plus, DakoCytomation) using the Envision plus system (DakoCytomation) for detection.

Specificity of Ab-1 was evaluated by preincubating Ab-1 with a 60-fold excess of KIT peptide (Oncogene) at room temperature for $2 \mathrm{~h}$ prior to staining.

The index cases were stained with additional antibodies against the following antigens: CD20, Bcl6, CD21, CD138, CD79a, CD3, latent membrane antigen-1 (LMP-1; DakoCytomation), CD5, CD10 (Novocastra, Burlingame, CA, USA), Bcl2 and p53 (Biogenex, San Ramon, CA, USA), using standard methods.

In situ hybridization was performed on the index cases and additional cases of plasmablastic lymphomas using EBVencoded viral RNA (EBER 1-2, Ventana, INFORM EBER, Tucson, AZ, USA), according to the manufacturer's protocol.

\section{Scoring of CD117 staining}

Semiquantitative assessment of the percentage of cells stained (PSC) and intensity of staining was performed by the authors (GB and EV), using a four-tiered scale (1+-4+ and $0-3+$, respectively). PSC was recorded as $1+, \leq 25 \%$ of cells stained; $2+,>25-50 \%$ of cells stained; $3+,>50-75 \%$ of cells stained; and $4+,>75 \%$ of cells stained. Mast cell staining was assigned an intensity score of $3+$ intermediate intensity of staining was scored as $2+$ while faint staining was scored as $1+$. Only cases with intensity score $\geq 2+$ were considered positive.

\section{Flow cytometric phenotyping}

Four-color flow cytometric analysis (FACScan; Becton Dickinson, San Diego, CA, USA) was performed using the Cell Quest software (Becton Dickinson) according to standard methods. A phycoerythrin-conjugated anti-CD117 antibody (mouse, monoclonal, clone 104D2, BD Biosciences, San Diego, CA, USA) was used that recognizes an extracellular epitope of CD117. Additional antibodies, directed against the 
following antigens, were used: CD3, CD19, CD20, CD79a (cytoplasmic), CD10, CD16/56, CD45, CD43, CD34, TdT, Kappa, Lambda, IgM, IgG, IgA, and IgD (BD Biosciences).

\section{RESULTS}

\section{Index cases}

\section{Case 1}

A 60-year-old HIV+ man presented with a soft-tissue mass of the left lower abdominal wall as well as mesenteric and retroperitoneal lymphadenopathy. Biopsy of the mass demonstrated a diffuse infiltrate composed predominantly of centroblasts (Fig. 1a), consistent with DLBCL. IHC staining demonstrated the following phenotype: CD20+, CD10+, bcl6+, bcl-2+, CD5-, and CD117+. IHC staining with Ab-1 (not shown) and A4502 (Fig. 1C) showed similar, albeit variable, intensity $(1+-3+)$ membranous staining in approximately $50 \%$ of cells. No staining was seen with Ab-1 after preincubation with KIT peptide. In situ hybridization with EBER was negative. Flow cytometry confirmed the phenotype, in addition demonstrating lambda light chain restriction and dim to moderate CD117 expression in $79 \%$ of the neoplastic cells (Fig. 1e). G-banded analysis demonstrated the translocation $\mathrm{t}(14 ; 18)$ (q32;q21) in association with a complex karyotype: $47, X Y, \quad \operatorname{add}(1)(p 36), \operatorname{del}(1)(q 21), 3, \operatorname{der}(6) t(6 ; 15)(q 10 ; q 10),+8$, add(9)(p12), $+\operatorname{del}(9)(q 13), \quad \operatorname{der}(13) t(1 ; 13)(q 25 ; q 34), t(14 ; 18)$ (q32;q21), $15 \times 2,17, \operatorname{add}(17)(p 13),+$ mar1-3[8]/46,XY[13] .

\section{Case 2}

A 63-year-old woman originally presented with an ulcerated gastric mass that on biopsy revealed a CD20+, bcl-6+, CD10(weak, partial)+, CD117- DLBCL associated with H. pylori infection. Ten months after treatment the patient developed a nasopharyngeal mass and cervical lymphadenopathy. Excisional biopsies showed diffuse, confluent infiltrates of plasmablasts replacing the cervical lymph node (Fig. 1b) and a large nodular infiltrate of plasmablasts in the nasal mucosa, consistent with plasmablastic lymphoma. The plasmablasts had the following phenotype: CD20-, CD79a+, bcl-6(weak)+, CD10-, CD138+, CD117+, and LMP-1-. IHC staining with Ab-1 (not shown) and A4502 (Fig. 1d) showed $1+-2+$ membranous staining in approximately $30 \%$ of cells. No staining was observed with Ab-1 after preincubation with KIT peptide. In situ hybridization with EBER was negative. Flow cytometry confirmed the phenotype, in addition demonstrating lambda light chain restriction, and dim CD117 expression in $25 \%$ of the neoplastic cells (Fig. 1f). G-banded analysis revealed a complex karyotype: $81-82,\langle 4 \mathrm{~N}\rangle, \mathrm{XX}$, $-\mathrm{X},-\mathrm{X},-1,-2, \operatorname{der}(3) \mathrm{t}(1 ; 3)(\mathrm{q} 21 ; \mathrm{q} 27) \times 2,4 \times 2,+\operatorname{del}(6)(\mathrm{q} 16) \times 2$, add(9)(p22), $13 \times 2$, add(14)(q32) $\times 2,16,17 \times 2,+$ mar1-6[cp5] . Fluorescence in situ hybridization confirmed the $\mathrm{IgH}$ rearrangement, but there was no evidence of BCL6 or MALT1 rearrangements. There was no evidence of a B-cell NHL or plasma cell dyscrasia on staging marrow biopsy. Six months after therapy the patient developed multiple lytic bone lesions and was found to have a monoclonal serum IgG lambda paraprotein as well as lambda Bence-Jones protein in the urine.

\section{CD117 staining of tissue microarrays}

Only 76/100 (76\%) microarray samples were evaluable due to partial or complete loss of tissue cores during processing and/or presence of drying artifact. These cases consisted of 56/74 DLBCL, 10/14 other B-cell NHL (two FL, four CLL/SLL, two MZBCL, twp MCL), 1/2 cHL, and 9/10 controls (six tissue controls and three cell lines). Subtypes of DLBCL analyzed included T-cell/histiocyte rich $(n=2)$, HIV-associated $(n=2)$, post-transplant $(n=4)$, Richter transformation of $\operatorname{CLL}(n=1)$, and transformed FL and MZBCL (one case each). Twentyone of $56(21 / 56,37 \%)$ of the microarray DLBCL stained with Ab-1 (Table 1). In all positive cases, PSC was either $3+$ or $4+$. Twelve cases $(21 \%)$ had $3+$ staining intensity (e.g. Fig. $2 b$ ) while nine $(16 \%)$ had $2+$ staining intensity (e.g. Fig. 2 e). In six cases (11\%), the pattern of staining was mixed, cytoplasmic and membranous (e.g. Fig. 2b) while the rest $(15 / 56,27 \%)$ showed fine granular cytoplasmic staining (e.g. Fig. 2e). It is important to point out that all the positive

Table 1 CD117 staining of tissue microarray B-cell lymphomas

\begin{tabular}{|c|c|c|c|c|c|c|c|}
\hline \multirow[b]{2}{*}{ Type of B-cell lymphoma } & \multicolumn{6}{|c|}{$A b-1$} & \multirow{2}{*}{$\begin{array}{c}\text { A4502 } \\
\text { no. } \\
\text { positive } \\
\text { cases }\end{array}$} \\
\hline & $\begin{array}{l}\text { No. positive } \\
\text { cases }\end{array}$ & $2+$ & $3+$ & $\mathrm{C}$ & $M$ and $C$ & $\begin{array}{c}\text { +KIT } \\
\text { peptide }\end{array}$ & \\
\hline Classical Hodgkin lymphoma & $1 / 1$ & $1 / 1$ & - & $1 / 1$ & - & ND & $0 / 1$ \\
\hline Follicular lymphoma & $0 / 2$ & - & - & - & - & $0 / 2$ & $0 / 2$ \\
\hline Mantle cell lymphoma & $0 / 2$ & - & - & - & - & $0 / 1$ & $0 / 2$ \\
\hline
\end{tabular}

C, cytoplasmic; CLL/SLL, chronic lymphocytic leukemia/small lymphocytic lymphoma; M, membranous; ND, not done.

Membranous staining in the absence of cytoplasmic staining was not seen in any of the microarray cases. 
Figure 1 Index cases (a,c,e, case 1; b,d,f, case 2). (a) Diffuse centroblastic proliferation (HE). (c) Immunohistochemical (IHC) staining with A4502 (dilution 1:400) demonstrating membranous staining of the neoplastic cells. (e) Dim to moderate KIT expression detected by flow cytometry (blue line indicates staining with isotype matched antibody, a negative control). (b) Diffuse plasmablastic proliferation in cervical lymph node (HE). (d) IHC staining with A4502 (dilution 1:400) demonstrating membranous staining of plasmablasts. (f) Dim KIT expression detected by flow cytometry (blue line indicates staining with isotype matched antibody, a negative control) (f).
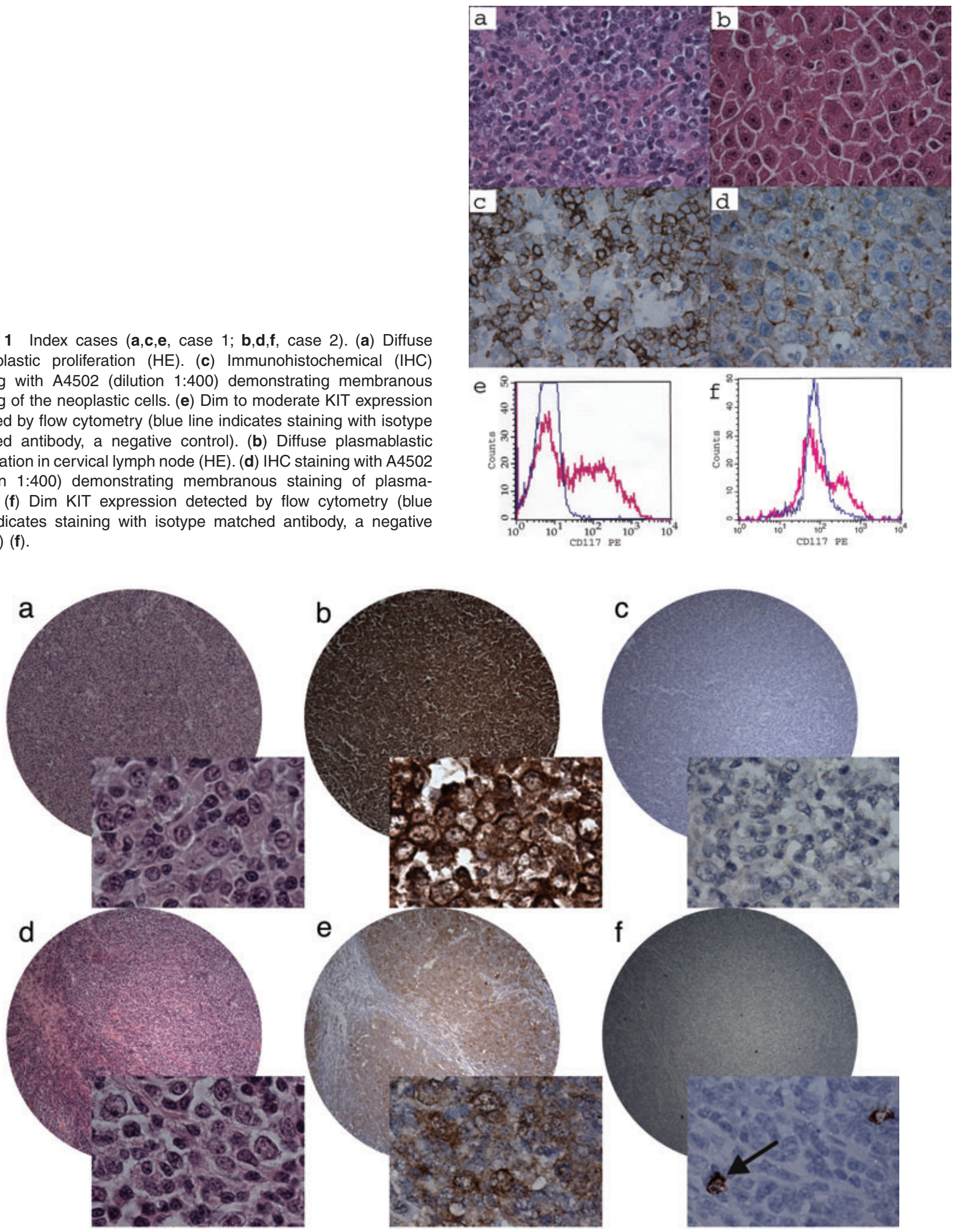

Figure 2 Representative tissue microarray cases (a-c, example 1; d-f, example 2). (a) HE staining example 1. (b) Immunohistochemical (IHC) staining with Ab-1 demonstrates 3+ intensity and a cytoplasmic and membranous staining pattern; (c) no staining is seen with A4502. (d) HE staining example 2. (e) IHC staining with Ab-1 demonstrates 2+ intensity and a cytoplasmic staining pattern; (f) neoplastic cells do not stain with A4502 but intratumoral mast cells show 3+ staining intensity (arrow). 
(as well as a few negative) cases with $A b-1$ had variable amounts of fine granular staining of the extracellular matrix and endothelial cells. Mast cells scattered amid neoplastic cells as well as in control tissue showed intense (3+) membranous as well as variable cytoplasmic staining.

Among the DLBCL subtypes, positive cases included one case of T-cell/histiocyte rich DLBCL (2+ cytoplasmic staining), one case of Richter transformation of CLL (3+ cytoplasmic staining), and one case of HIV-associated DLBCL (2+ cytoplasmic staining). One case of $\mathrm{cHL}$ had 2+ cytoplasmic staining of Hodgkin and Reed-Sternberg cells but no staining was observed in any case of FL, CLL/SLL, MCL, or MZBCL (Table 1). The two Burkitt cell lines were negative, while the EBV transformed lymphoblastoid cell line had 3+ cytoplasmic staining.

On IHC staining with Ab-1 after preincubation with KIT peptide (using one of the tissue microarrays containing 30 evaluable cases of DLBCL), 4/30 cases (13\%) showed persistent fine granular cytoplasmic and stromal staining. These represented $4 / 14$ (29\%) of the previously positive cases.

A4502 did not stain any of the tissue microarray cases (representative examples Fig. 2c,f). Mast cells in control tissues and in lymphoma cases, where present, had 3+ staining (Fig. 2f).

\section{CD117 staining of additional plasmablastic lymphomas}

Only $1 / 2$ of the EBV- (LMP-1-, EBER-) plasmablastic lymphomas had 2+ membranous and faint cytoplasmic staining in approximately $80 \%$ of the neoplastic cells with both A4502 and $A b-1$. Both of these cases had concurrent marrow involvement. None of the five EBV+ (LMP-1-, EBER+) plasmablastic lymphomas stained with either antibody and none of these cases had bone marrow disease.

\section{DISCUSSION}

KIT/SCF interactions are reportedly not required for normal $\mathrm{B}$-cell development ${ }^{32}$ and $\mathrm{KIT}$ expression is rare in B-lineage ALL. ${ }^{2}$ Only a limited number of studies have analyzed KIT expression in lymphomas and most of these have focused on CD30+ lymphomas including $\mathrm{CHL}$ and $\mathrm{ALCL} .{ }^{24-26}$ Natkunam and Rouse and Pinto et al. reported a lack of CD117 expression in three and eight cases of DLBCL, respectively, ${ }^{21,24}$ while Chen et al. reported weak cytoplasmic staining in 1/28 DLBCL. ${ }^{20}$ In all these studies, DLBCL were part of the comparison or control groups where CD117 expression was being evaluated in other hematopoietic neoplasms. Nakatsuka et al. reported mutations in exons 11 and 15 in 9/15 adrenal DLBCL, but expression of KIT protein was not assessed in that study. ${ }^{33}$
We validated CD117 expression in the present two index cases with three different antibodies. Tissue staining with Ab-1 and A4502 demonstrated a membranous staining pattern of variable intensity (Fig. 1c,d) while flow cytometry, with an antibody directed against an undefined cell surface epitope, detected dim to moderate KIT expression in both cases (Fig. 1e,f). In our analysis of DLBCL using tissue microarrays, however, discordant results were observed with the two polyclonal CD117 antibodies. Both antibodies are directed against the carboxy-terminus of the c-kit gene product, and have overlapping epitopes. Predominantly cytoplasmic staining (Fig. 2b,e) was seen in a significant proportion $(21 / 56,37 \%)$ of the microarray DLBCL with $A b-1$, while none of these cases stained with A4502. To examine the specificity of $A b-1$, a subset of cases (one tissue microarray containing 30 DLBCL) was incubated with $\mathrm{Ab}-1$ and KIT peptide prior to staining. Persistent, cytoplasmic (and stromal), fine granular staining was observed in $4 / 30$ cases (13\%) despite preadsorption with the peptide. Although the presence of KIT cross-reactive epitopes cannot be entirely excluded in some DLBCL, we believe that the predominant cytoplasmic staining pattern, staining of stromal and endothelial cells, and persistent staining with $\mathrm{Ab}-1$, despite preincubation with KIT peptide, are features of non-specific binding (by antibodies directed against KIT as well as other antibodies in the polyclonal mixture).

Based on IHC staining results with A4502, CD117 expression appears to be rare in DLBCL. To confirm this observation we prospectively analyzed CD117 expression in seven additional DLBCL by flow cytometry and found all cases to be negative (data not shown). One of these cases was positive by IHC staining with $A b-1$, but negative with $A 4502$, further supporting our view of non-specific staining by $A b-1$.

Quantification of CD117 mRNA levels was not possible in any of the DLBCL studied by IHC due to the lack of frozen tissue availability but we did examine CD117 mRNA expression levels in another dataset of lymphomas that included 46 DLBCL (including nine HIV-associated), six DLBCL cell lines, nine Burkitt lymphomas (including seven HIV-associated) and nine primary effusion lymphomas (Klein $U$, unpubl. data 2003, available at http://icg.cpmc.columbia.edu/Web_Data/ PEL_Data/Klein_PEL_2003.htm). Interestingly, an elevated c-kit mRNA level was observed in 1/7 HIV-associated Burkitt lymphomas (but none of the DLBCL). This is consistent with the IHC staining results with $\mathrm{A} 4502$, confirming the rarity of CD117 expression in DLBCL.

We tested two different CD117 antibodies because conflicting results for KIT expression have been reported for a subset of lymphomas. ${ }^{24,25,34,35}$ Pinto et al. detected CD117 expression in a significant number of $\mathrm{cHL}$ and ALCL cases using the monoclonal antibody 17F11 (Immunotech, Marseille, France), which recognizes an extracellular epitope of $\mathrm{KIT}^{24,25}$ In contrast, Rassidakis et al. using the A4502 
antibody, found only one positive ALCL in an analysis of 183 CD30+ lymphomas. ${ }^{26,35}$ These investigators also reported an absence of $c$-kit mRNA expression in seven $\mathrm{cHL}$ and five ALCL cell lines by reverse transcription-polymerase chain reaction. Using the same antibody (A4502) Brown and Nazmi reported cytoplasmic staining in $3 / 10$ cases of $\mathrm{cHL}$, nodular sclerosing subtype, although the dilution of the antibody used was not reported and no images were available for review. ${ }^{34}$ It is interesting to note that the single evaluable case of $\mathrm{cHL}$ in the present microarray displayed 2+ cytoplasmic staining with Ab-1 but did not stain with A4502, similar to the results of Rassidakis et al. ${ }^{26,35}$

Disparate staining results for CD117 have also been reported for other neoplasms, including intra-abdominal desmoids. Yantiss et al. showed KIT immunoreactivity in 9/12 intra-abdominal desmoids using A4502 (1:30), ${ }^{36}$ while Hornick and Fletcher using the same antibody at 1:250 dilution found only focal, weak staining in 1/20 desmoids. ${ }^{37}$ Similarly, Miettinen using the rabbit polyclonal antibody sc-168 (Santa Cruz Biotechnology, San Franscisco, CA, USA) at a 1:400 dilution could not detect staining in 14 tumors analyzed. ${ }^{38}$ In an attempt to resolve these disparate results, Lucas et al. compared two antibodies, C-19 (Santa Cruz Biotechnology), which recognizes an epitope on amino acids 959-973, and A4502, at different dilutions. ${ }^{39}$ They found that the best results were obtained with A4502 at a dilution of 1:250 and using these conditions desmoids could be regarded as KITtumors. In our hands an even higher dilution of A4502 (1:400) provided consistent staining of controls as well as the index cases, and was, thus, used for higher stringency.

In the present study the discordant results obtained with the two antibodies, due to false-positive (non-specific) staining with $A b-1$, reinforces the need for critical evaluation of IHC reagents. False-positive results can pose an important diagnostic problem. For example, we recently encountered a case of primary CNS DLBCL (data not shown), which stained strongly with $A b-1$, raising the possibility of a germinoma before a panel of hematopoietic markers confirmed the diagnosis of lymphoma. This lymphoma did not stain with A4502.

To date only rare cases of CD117+ B-cell NHL have been reported. A single case of a CD117+ CD5+ B-cell NHL carrying the translocation $\mathrm{t}(14 ; 18)(\mathrm{q} 32 ; \mathrm{q} 21)$ was reported by Bravo et al. but these authors did not detect CD117 expression in a survey of 50 low-grade B-cell chronic lymphoproliferative disorders that included CLL and lymphoplasmacytic lymphomas. ${ }^{40} \mathrm{CD} 117$ expression has also been observed in rare cases $(1.17 \%)$ of mantle cell lymphoma ${ }^{41}$ but was reportedly absent in an analysis of 13 Burkitt cell lines and seven Burkitt lymphomas. ${ }^{42}$ During preparation of the present manuscript, Zimpfer et al. published the results of a survey of CD117 expression in 733 cases of B-NHL (including 385 cases of DLBCL) using antibody A4502 (dilution 1:300). ${ }^{43}$ They found two CD117+ lymphomas, one case each of folli- cular lymphoma and peripheral T-cell lymphoma not otherwise specified, but all DLBCL were negative.

The significance of KIT expression in these cases as well as in the present index case of DLBCL of follicle center-cell origin is unclear. No activating mutations of the c-kit gene were found in the two CD117+ lymphomas reported by Zimpfer et al. ${ }^{43} \mathrm{~A}$ ligand-dependent mode of CD117 upregulation has been proposed for these cases $^{43}$ and other CD117+ neoplasms lacking $c$-kit mutations, including small cell lung carcinomas and breast carcinomas. ${ }^{44}$ Variable staining intensity of only a proportion of cells observed in the present cases, also favors a secondary inductive effect as the mechanism responsible for KIT expression (rather than an activating mutation).

Two of eight $(25 \%)$ plasmablastic lymphomas analyzed (including one of the present index cases) were CD117+ on IHC staining; these represented 2/3 (67\%) EBV- plasmablastic lymphomas with bone marrow involvement. Neoplasms with plasmablastic differentiation comprise a heterogeneous group of entities that include HIV-associated lymphomas of the oral cavity (and other sites), primary effusion lymphomas, anaplastic lymphoma kinase+ DLBCL, Kaposi sarcoma herpes virus-associated lymphomas arising in the background of plasma cell variant of Castleman's disease, a subset of post-transplant lymphomas, and extramedullary plasmacytomas. ${ }^{45-49}$ All these neoplasms share morphological and phenotypic similarities with subtle variations. Distinguishing plasmablastic lymphomas from extramedullary plasmacytomas with plasmablastic morphology is not possible with the current armamentarium of monoclonal antibodies. ${ }^{50}$ The present results, in conjunction with those of Bayer-Garner et al., suggest that EBV- plasmablastic neoplasms associated with medullary disease or a plasma cell dyscrasia often express CD117, and, thus, staining for CD117 might help in differentiating these neoplasms from other types of plasmablastic lymphomas. ${ }^{51}$ CD117 is expressed in a subset of multiple myelomas. ${ }^{23,52}$ Lemoli et al. demonstrated a heterogeneous pattern of SCF (kit ligand) expression and a proliferative response to the same cytokine by multiple myeloma cell lines, ${ }^{53}$ suggesting that CD117 expression in a subset of multiple myeloma cases may be ligand dependent. Moreoever, activating $c$-kit mutations have not been identified in the limited number of multiple myeloma cases analyzed, ${ }^{54}$ and the efficacy of KIT inhibitors in the treatment of CD117+ plasma cell neoplasms remains to be determined.

In conclusion, KIT expression can be seen sporadically in DLBCL of follicle center-cell origin. Additionally, staining for CD117 might help in identifying EBV- plasmablastic lymphomas associated with medullary disease. Finally, our experience with the two different CD117 antibodies further reinforces the need for careful validation of $\mathrm{IHC}$ staining for KIT because of the possible therapeutic implications. 


\section{ACKNOWLEDGMENTS}

We thank Dr Rita Shaknovich for providing the tissue microarrays, Dr Christian Keller for technical assistance, and Ms Dianne Alexis for help with immunohistochemical staining.

\section{REFERENCES}

1 Horie K, Fujita J, Takakura $\mathrm{K}$ et al. The expression of c-kit protein in human adult and fetal tissues. Hum Reprod 1993; 8: 1955-62.

2 Escribano L, Ocqueteau M, Almeida J, Orfao A, San Miguel JF. Expression of the c-kit (CD117) molecule in normal and malignant hematopoiesis. Leuk Lymphoma 1998; 30: 459-66.

3 Ishikawa K, Komuro T, Hirota S, Kitamura Y. Ultrastructural identification of the c-kit-expressing interstitial cells in the rat stomach: A comparison of control and Ws/Ws mutant rats. Cell Tissue Res 1997; 289: 137-43.

4 Austen KF, Boyce JA. Mast cell lineage development and phenotypic regulation. Leuk Res 2001; 25: 511-18.

5 Huizinga JD, Thuneberg L, Kluppel M, Malysz J, Mikkelsen $H B$, Bernstein A. W/kit gene required for interstitial cells of Cajal and for intestinal pacemaker activity. Nature 1995; 373: 347-9.

6 Lyman SD, Jacobsen SE. c-kit ligand and Flt3 ligand: Stem/ progenitor cell factors with overlapping yet distinct activities. Blood 1998; 91: 1101-34.

7 Loveland KL, Schlatt S. Stem cell factor and c-kit in the mammalian testis: Lessons originating from Mother Nature's gene knockouts. J Endocrinol 1997; 153: 337-44.

8 Wehrle-Haller B. The role of Kit-ligand in melanocyte development and epidermal homeostasis. Pigment Cell Res 2003; 16: 287-96.

9 Heinrich MC, Rubin BP, Longley BJ, Fletcher JA. Biology and genetic aspects of gastrointestinal stromal tumors: KIT activation and cytogenetic alterations. Hum Pathol 2002; 33: 484-95.

10 Kemmer K, Corless CL, Fletcher JA et al. KIT mutations are common in testicular seminomas. Am J Pathol 2004; 164: 30513.

11 Longley BJ Jr, Metcalfe DD, Tharp $\mathrm{M}$ et al. Activating and dominant inactivating c-KIT catalytic domain mutations in distinct clinical forms of human mastocytosis. Proc Natl Acad Sci USA 1999; 96: 1609-14.

12 Clark JJ, Smith FO, Arceci RJ. Update in childhood acute myeloid leukemia: Recent developments in the molecular basis of disease and novel therapies. Curr Opin Hematol 2003; 10: 31-9.

13 Makhlouf HR, Remotti HE, Ishak KG. Expression of KIT (CD117) in angiomyolipoma. Am J Surg Pathol 2002; 26: 4937.

14 Sekido $\mathrm{Y}$, Obata $\mathrm{Y}$, Ueda R et al. Preferential expression of ckit protooncogene transcripts in small cell lung cancer. Cancer Res 1991; 51: 2416-19.

15 Lin ZH, Han EM, Lee ES et al. A distinct expression pattern and point mutation of c-kit in papillary renal cell carcinomas. Mod Pathol 2004; 17: 611-16.

16 Mino M, Pilch BZ, Faquin WC. Expression of KIT (CD117) in neoplasms of the head and neck: An ancillary marker for adenoid cystic carcinoma. Mod Pathol 2003; 16: 1224-31.

17 Bar-Sela G, Kuten A, Ben-Eliezer S, Gov-Ari E, Ben-Izhak O. Expression of HER2 and C-KIT in nasopharyngeal carcinoma:
Implications for a new therapeutic approach. Mod Pathol 2003; 16: 1035-40.

18 Chui $\mathrm{X}$, Egami $\mathrm{H}$, Yamashita $\mathrm{J}$ et al. Immunohistochemical expression of the c-kit proto-oncogene product in human malignant and non-malignant breast tissues. Br J Cancer 1996; 73: 1233-6.

19 Smithey BE, Pappo AS, Hill DA. C-kit expression in pediatric solid tumors: A comparative immunohistochemical study. Am J Surg Pathol 2002; 26: 486-92.

20 Chen J, Yanuck RR III, Abbondanzo SL, Chu WS, Aguilera NS. c-Kit (CD117) reactivity in extramedullary myeloid tumor/ granulocytic sarcoma. Arch Pathol Lab Med 2001; 125: 144852.

21 Natkunam Y, Rouse RV. Utility of paraffin section immunohistochemistry for C-KIT (CD117) in the differential diagnosis of systemic mast cell disease involving the bone marrow. $A m \mathrm{~J}$ Surg Pathol 2000; 24: 81-91.

22 Sykora KW, Tomeczkowski J, Reiter A. C-kit receptors in childhood malignant lymphoblastic cells. Leuk Lymphoma 1997; 25: 201-16.

23 Ocqueteau M, Orfao A, Garcia-Sanz R, Almeida J, Gonzalez M, San Miguel JF. Expression of the CD117 antigen (c-Kit) on normal and myelomatous plasma cells. Br J Haematol 1996; 95: 489-93.

24 Pinto A, Gloghini A, Gattei V, Aldinucci D, Zagonel V, Carbone A. Expression of the c-kit receptor in human lymphomas is restricted to Hodgkin's disease and CD30+ anaplastic large cell lymphomas. Blood 1994; 83: 785-92.

25 Aldinucci D, Poletto D, Nanni $\mathrm{P}$ et al. Hodgkin and ReedSternberg cells express functional c-kit receptors and interact with primary fibroblasts from Hodgkin's disease-involved lymph nodes through soluble and membrane-bound stem cell factor. Br J Haematol 2002; 118: 1055-64.

26 Rassidakis GZ, Georgakis GV, Oyarzo M, Younes A, Medeiros LJ. Lack of c-kit (CD117) expression in CD30+ lymphomas and lymphomatoid papulosis. Mod Pathol 2004; 17: 946-53.

27 Gatter KC, Warnke RA. Diffuse large B-cell lymphoma. In: Jaffe ES, Harris NL, Stein H, Vardiman JW, eds. World Health Organization Classification of Tumors Pathology and Genetics of Tumours of Haematopoietic and Lymphoid Tissues. Lyon: IARC Press, 2001; 171-4.

28 Alizadeh AA, Eisen MB, Davis RE et al. Distinct types of diffuse large $\mathrm{B}$-cell lymphoma identified by gene expression profiling. Nature 2000; 403: 503-11.

29 Schlegelberger B. Cytogenetic subtyping of diffuse large B-cell lymphomas. Ann Hematol 2001; 80 (Suppl. 3): B32-34.

30 de Leval L, Harris NL. Variability in immunophenotype in diffuse large B-cell lymphoma and its clinical relevance. Histopathology 2003; 43: 509-28.

31 Shaknovich R, Celestine A, Yang L, Cattoretti G. Novel relational database for tissue microarray analysis. Arch Pathol Lab Med 2003; 127: 492-4.

32 Takeda S, Shimizu T, Rodewald HR. Interactions between c-kit and stem cell factor are not required for B-cell development in vivo. Blood 1997; 89: 518-25.

33 Nakatsuka S, Hongyo T, Syaifudin M, Nomura T, Shingu N, Aozasa K. Mutations of p53, c-kit, K-ras, and beta-catenin gene in non-Hodgkin's lymphoma of adrenal gland. Jpn J Cancer Res 2002; 93: 267-74.

34 Brown RE, Nazmi RK. The Reed-Steinberg cell: Molecular characterization by proteomic analysis with therapeutic implications. Ann Clin Lab Sci 2002; 32: 339-51.

35 Rassidakis GZ, Georgakis GV, Younes A, Medeiros LJ. c-kit is not expressed in Hodgkin disease and anaplastic lymphoma kinase (ALK)-positive anaplastic large cell lymphoma. Blood 2003; 102: 4619-20. 
36 Yantiss RK, Spiro IJ, Compton CC, Rosenberg AE. Gastrointestinal stromal tumor versus intra-abdominal fibromatosis of the bowel wall: A clinically important differential diagnosis. Am J Surg Pathol 2000; 24: 947-57.

37 Hornick JL, Fletcher CD. Immunohistochemical staining for KIT (CD117) in soft tissue sarcomas is very limited in distribution. Am J Clin Pathol 2002; 117: 188-93.

38 Miettinen M. Are desmoid tumors kit positive? Am J Surg Pathol 2001; 25: 549-50.

39 Lucas DR, al-Abbadi M, Tabaczka P, Hamre MR, Weaver DW, Mott MJ. c-Kit expression in desmoid fibromatosis. Comparative immunohistochemical evaluation of two commercial antibodies. Am J Clin Pathol 2003; 119: 339-45.

40 Bravo P, Agustin BD, Bellas $\mathrm{C}$ et al. Expression of high amounts of the CD117 molecule in a case of B-cell nonHodgkin's lymphoma carrying the $\mathrm{t}(14: 18)$ translocation. Am J Hematol 2000; 63: 226-9.

41 Potti A, Ganti AK, Kargas S, Koch M. Immunohistochemical detection of C-kit (CD117) and vascular endothelial growth factor (VEGF) overexpression in mantle cell lymphoma. Anticancer Res 2002; 22: 2899-901.

42 Tomeczkowski J, Beilken A, Frick D et al. Absence of c-kit receptor and absent proliferative response to stem cell factor in childhood Burkitt's lymphoma cells. Blood 1995; 86: 146980.

43 Zimpfer A, Went $\mathrm{P}$, Tzankov $\mathrm{A}$ et al. Rare expression of KIT (CD117) in lymphomas: A tissue microarray study of 1166 cases. Histopathology 2004; 45: 398-404.

44 Heinrich MC, Blanke CD, Druker BJ, Corless CL. Inhibition of KIT tyrosine kinase activity: A novel molecular approach to the treatment of KIT-positive malignancies. J Clin Oncol 2002; 20: 1692-703.

45 Delecluse HJ, Anagnostopoulos I, Dallenbach F et al. Plasmablastic lymphomas of the oral cavity: A new entity associated with the human immunodeficiency virus infection. Blood 1997; 89: 1413-20.

46 Klein U, Gloghini A, Gaidano $\mathrm{G}$ et al. Gene expression profile analysis of AIDS-related primary effusion lymphoma (PEL) suggests a plasmablastic derivation and identifies PEL-specific transcripts. Blood 2003; 101: 4115-21.

47 Colomo L, Loong F, Rives S et al. Diffuse large B-cell lymphomas with plasmablastic differentiation represent a heterogeneous group of disease entities. Am J Surg Pathol 2004; 28: 736-47.

48 Gascoyne RD, Lamant L, Martin-Subero Jl et al. ALK-positive diffuse large B-cell lymphoma is associated with Clathrin-ALK rearrangements: Report of 6 cases. Blood 2003; 102: 2568-73.

49 Du MQ, Diss TC, Liu H et al. KSHV- and EBV-associated germinotropic lymphoproliferative disorder. Blood 2002; 100: 3415-18.

50 Vega F, Chang CC, Medeiros LJ et al. Plasmablastic lymphomas and plasmablastic plasma cell myelomas have nearly identical immunophenotypic profiles. Mod Pathol 2004; 18: 806-15.

51 Bayer-Garner IB, Schwartz MR, Lin P, Smoller BR. CD117, but not lysozyme, is positive in cutaneous plasmacytoma. Arch Pathol Lab Med 2003; 127: 1596-8.

52 Kraj M, Poglod R, Kopec-Szlezak J, Sokolowska U, Wozniak J, Kruk B. C-kit receptor (CD117) expression on plasma cells in monoclonal gammopathies. Leuk Lymphoma 2004; 45: 22819.

53 Lemoli RM, Fortuna A, Grande A et al. Expression and functional role of c-kit ligand (SCF) in human multiple myeloma cells. Br J Haematol 1994; 88: 760-69.

54 Lugli A, Went P, Khanlari B, Nikolova Z, Dirnhofer S. Rare KIT (CD117) expression in multiple myeloma abrogates the usefulness of imatinib mesylate treatment. Virchows Arch 2004; 444: 264-8. 